\title{
ANATOMICAL STUDY ON THE LATERAL SUPRAPATELLAR ACCESS ROUTE FOR LOCKED INTRAMEDULLARY NAILS IN TIBIAL FRACTURES
}

Italo Scanavini Cerqueira', Pedro Araujo Petersen', Rames Mattar Júnior ${ }^{2}$, Jorge dos Santos Silva ${ }^{3}$, Paulo Reis $^{4}$, Guilherme Pelosini Gaiarsa ${ }^{4}$, Massimo Morandi ${ }^{5}$

\section{ABSTRACT}

Objective: Intramedullary nails are the gold standard for treating tibial shaft fractures. Knee pain is a frequent complication after the procedure. Alternative routes such as the suprapatellar approach for nail insertion are seen as an option for avoiding late postoperative knee pain. The question is whether this approach might give rise to any injury to intra-articular structures of the knee. Methods: This study analyzed the suprapatellar approach and the risk to adjacent structures by reproducing it in 10 knees of five cadavers. Results: This approach was seen to make it easy to locate the entry point, with lesions only occurring in the Hoffa fat. In three of our cases, there were lesions of the chondral surface, which is an obstacle that is difficult to overcome. Conclusion: There is a need to develop specific material to minimize injury to intra-articular structures when using this route.

Keywords - Tibial Fractures; Orthopedic Procedures; Fracture Fixation, Intramedullary

\section{INTRODUCTION}

Intramedullary nails are currently considered to be the gold standard for treating tibial shaft fractures. One of the most frequent complications that has to be combated is knee pain after the procedure, and even more chronically, after consolidation. According to some authors, chronic knee pain may affect more than $50 \%$ of the cases ${ }^{(1-4)}$.

With the aim of avoiding this symptom, alternative routes for inserting the nail have been used, including by means of the lateral patellar paratendon, medial patellar paratendon or transtendon. However, these alternatives seem not to make any difference regarding the incidence of post-treatment pain, and even removal of the nail often does not improve this complication ${ }^{(5)}$.

One possibility is to change the access route so as to avoid such a close relationship with the patellar tendon. Lesions of this tendon are associated at different levels with knee pain after implantation of an intramedullary nail ${ }^{(6-8)}$.

Because suprapatellar routes do not injure the tendon, they consequently lead to lower levels of chronic knee pain after implant placement, or even absence of pain.

Such routes have also been used for other reasons, such as for religious patients, especially Muslims, for whom the scar in the patellar tendon region makes the act of kneeling to pray difficult, and among afro-descendents, in whom formation of chloride in incisions close to the tendon occurs more readily, which restricts the range of motion of the affected knee ${ }^{(9)}$.

Other questions that remain are whether, with this new route, there is any injury to the intra-articular structures of the knee; and what consequences to the

1 - Resident in Orthopedics and Traumatology, Institute of Orthopedics and Traumatology, HC-FMUSP, São Paulo, SP, Brazil.

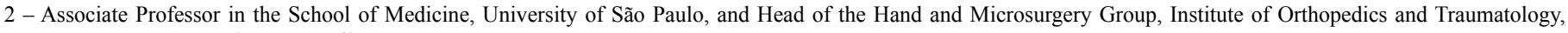
HC-FMUSP, São Paulo, SP, Brazil.

3 - Attending Physician and Head of the Traumatology Group, Institute of Orthopedics and Traumatology, HC-FMUSP, São Paulo, SP, Brazil.

4 - Attending Physician in the Traumatology and Reconstruction Group, Institute of Orthopedics and Traumatology, HC-FMUSP, São Paulo, SP, Brazil.

5 - Head of the Trauma Service, Henry Ford Hospital, Detroit, USA.

Work performed at the Medical Investigation Laboratory for the Musculoskeletal System (LIM41), Department of Orthopedics and Traumatology, FMUSP. Correspondence: Rua Dr. Ovídio Pires de Campos 333, Cerqueira Cesar, 05403-010 São Paulo, SP, Brazil. E-mail: italosca@yahoo.com.br Work received for publication: May 25, 2011; accepted for publication: September 19, 2011.

The authors declare that there was no conflict of interest in conducting this work 
future clinical conditions these lesions would cause, in relation to the route generally used (patellar transtendon). Moreover, it needs to be known whether these consequences are of low enough importance to justify using this route, in order to diminish or do away with knee pain caused by patellar tendon injuries.

Tornetta and Collins ${ }^{(10)}$, Tornetta et $\mathrm{al}^{(11)}$ and McConnell et $\mathrm{al}^{(12)}$ described an expanded lateral parapatellar access, with good access to the trochlear fossa for implanting an intramedullary nail with the leg extended, this making it possible to use nails in fractures that are more proximal, with less displacement due to muscle forces. They reported that in the first case, there was a small cartilage lesion with this procedure, but with good results subsequently.

In 2010, Morandi et al ${ }^{(13)}$ described a lateral suprapatellar route in semi-extension, as an option for these fractures, and for patients for whom an anterior scar in the knee would be problematic, such as religious individuals who spend much time kneeling, patients with a tendency to form cheloids or other special cases of wounds in the region of the access route.

\section{OBJECTIVES}

The objective of this study was to evaluate the possibility of using this suprapatellar surgical access to introduce the intramedullary nail for the tibia, with comparisons between a variety of data, such as access to the correct entry point, the safety zone and difficulties in correctly positioning the guidewire for the intramedullary nail; and to identify the structures that may become injured with this access route, which could be the joint cartilage of the femur, or the posterior face of the patella, or the patellar tendon itself. Thus, the study aimed to indirectly predict whether postimplantation knee pain could be diminished or even done away with, through using this alternative route, without producing new complications due to intraarticular lesions.

\section{MATERIALS AND METHODS}

Ten knees from five cadavers of differing ages and sex were dissected at the Death Investigation Service of the University of São Paulo (SVOC-USP), in which the cause of death did not involve fracture of the lower limbs or local deformities, in order to obtain data to use regarding this access route.

By means of a lateral suprapatellar access route of $2.5 \mathrm{~cm}$ (Figure 1) a previously cut $10 \mathrm{~cm}^{3}$ syringe was inserted to serve as a cannulated guide. This was placed under the patella, going in the direction of the tibia. A Steinmann wire of $3 \mathrm{~mm}$ in thickness was passed through it and was attached to the tibia at the point of entry immediately laterally to the projection of the anterior crest of the tibia, without using radioscopy (Figure 2).

Following this, after careful dissection, an access route was constructed going from the lateral apex of the patella to the insertion of the patellar tendon, to reach the knee joint under direct viewing. The guide was viewed anteriorly to the femoral trochlea and was placed under the patella (Figure 3).

\section{The following were evaluated:}

- Precision of blind positioning of the point of entry; - Structures at risk during this procedure, such as the Hoffa fat, patellar tendon, menisci and joint cartilage; - Whether any chondral lesion was caused by the guide during its insertion;

- Anatomical repairs that might make using this route difficult.

\section{RESULTS}

In the 10 knees from the five cadavers, the distance from the suprapatellar incision to the point of entry of the guidewire ranged from 94 to $110 \mathrm{~mm}$. The anatomical repairs that caused difficulty in introducing the guide were noted: the trochlea and the Hoffa fat were highlighted in eight knees, while there were only two knees without resistance from any tissues. The point of entry was not reached in two of the knees, and the distance from the guide insertion to the correct location of the entry point ranged from 0 to $4 \mathrm{~mm}$ (Table 1 ).

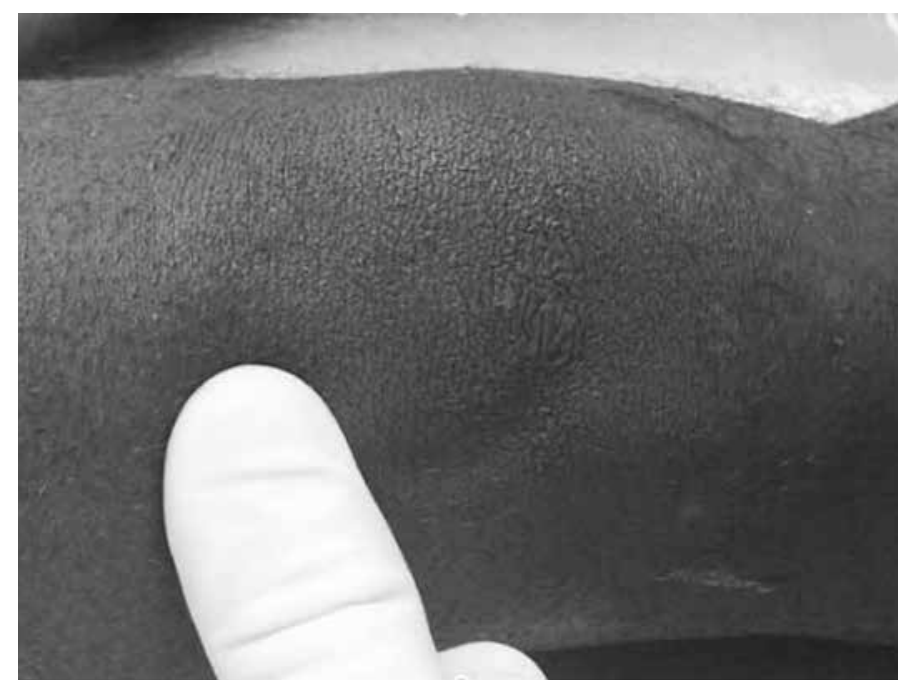

Figure 1 - Position of the incision: $2.5 \mathrm{~cm}$ above the superolateral corner of the patella. 


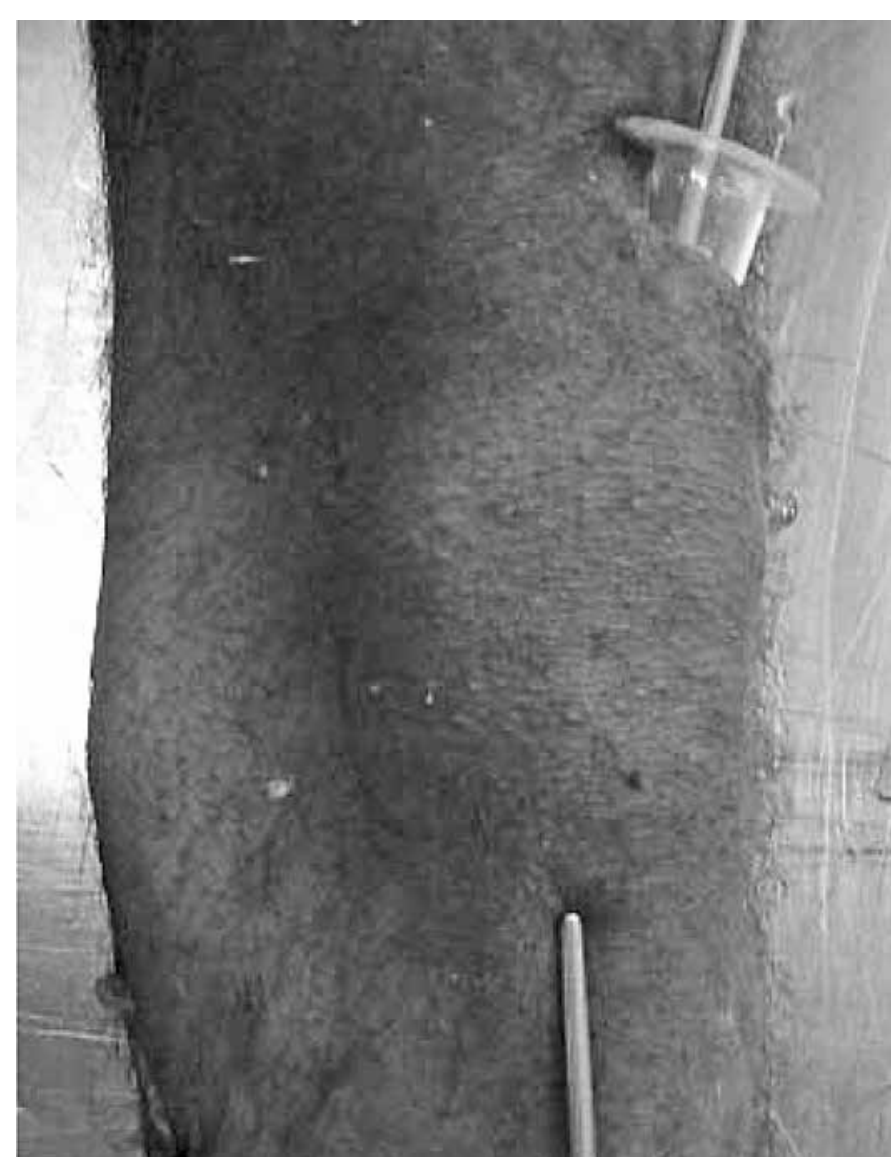

Figure 2 - Soft-tissue protector positioned using guidewire, demonstrating the ease of locating the entry point, and external wire showing direction of the tibial medullary canal.

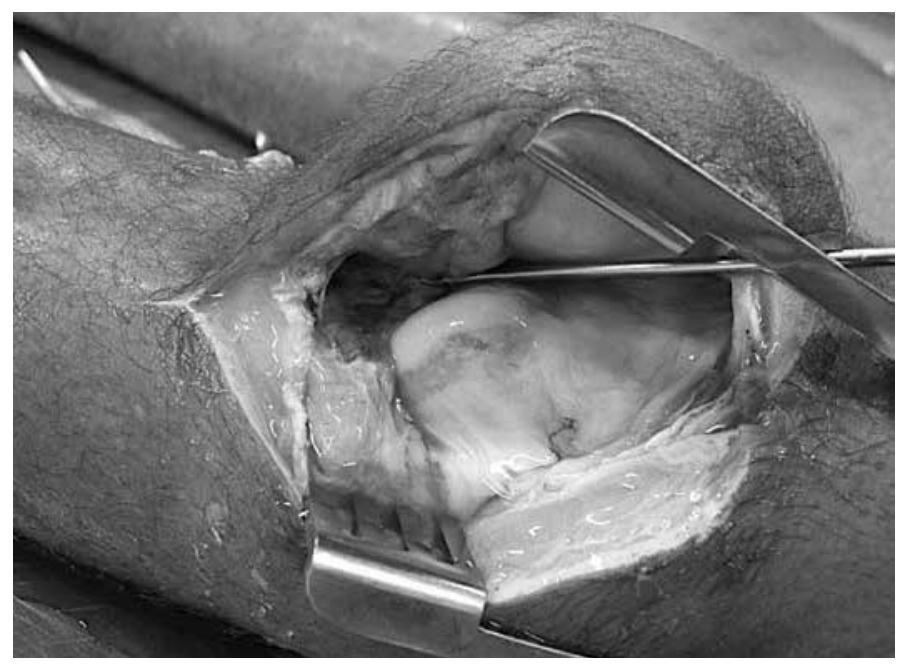

Figure 3-Guidewire at the point of entry and area of the trochlea at the start of the cartilage: a point that was difficult to surmount with a malleable protector (not shown in this figure).

\section{DISCUSSION}

Since the first description of intramedullary nails by Kuntscher ${ }^{(14)}$ and the modification by Grosse et $\mathrm{al}^{(15)}$ that created locked nails, infrapatellar access routes have been used. These could be medial, lateral
Table 1 - List of entry points with local anatomical structures.

\begin{tabular}{c|c|c|c|c|c}
\hline Case & Side & Entry point & $\begin{array}{c}\text { Structures } \\
\text { crossed }\end{array}$ & $\begin{array}{c}\text { Distance } \\
\text { from } \\
\text { incision to } \\
\text { entrance }\end{array}$ & Repairs \\
\hline 1 & R & $\begin{array}{c}4 \mathrm{~mm} \\
\text { anteriorly }\end{array}$ & HF & $105 \mathrm{~mm}$ & HF \\
\hline 1 & L & $3 \mathrm{~mm}$ medially & HF & $104 \mathrm{~mm}$ & HF \\
\hline 2 & R & Correct & HF & $110 \mathrm{~mm}$ & Trochlea \\
\hline 2 & L & Correct & HF & $110 \mathrm{~mm}$ & Trochlea \\
\hline 3 & R & Not reached & PA & $95 \mathrm{~mm}$ & None \\
\hline 3 & L & Not reached & PA & $94 \mathrm{~mm}$ & None \\
\hline 4 & R & $\begin{array}{c}2 \text { mm } \\
\text { posteriorly }\end{array}$ & HF & $103 \mathrm{~mm}$ & Trochlea \\
\hline 4 & L & $2 \mathrm{~mm}$ medially & HF & $103 \mathrm{~mm}$ & Trochlea \\
\hline 5 & R & 4 mm laterally & HF and PT & $110 \mathrm{~mm}$ & HF \\
\hline 5 & L & 3 mm laterally & HF and PT & $110 \mathrm{~mm}$ & HF \\
\hline PT - patellar tendon; HF - Hoffa fat; PA - Pes anserinus. & &
\end{tabular}

or patellar transtendon routes.

The discussion on the best access route and the incidence of anterior knee pain has been extensive and has given rise to controversy.

Studies by Keating et a ${ }^{(16)}$ demonstrated that there is a high correlation between the transtendon route and anterior knee pain, while Väistö et $\mathrm{al}^{(4,6)}$ did not find any relationship between anterior pain and the access route. No author has been able to correlate nail protrusion in the proximal cortical bone with anterior knee pain, and this has led several authors to conclude that the cause of the pain was related to local surgical manipulation and lesions of the infrapatellar nerve.

Court-Brown et al ${ }^{(17)}$ correlated anterior pain with age. They showed that it is much more frequent in young and active patients, and that it causes great difficulty in kneeling, with pain presented even at rest.

In 1996, concerned about the antecurvatum deformity that occurs through using intramedullary nails in fractures that are more proximal in the tibia, Tornetta and Collins ${ }^{(10)}$ and Tornetta and Ryan ${ }^{(18)}$ described a semi-extended position with a wide lateral parapatellar route, using the trochlea as a guide for locating the point of entry. In 2007, the same authors described a percutaneous route through a lateral suprapatellar incision, using a cannula and a trocar. This route enabled easy access to the safe point of entry described previously, and reduced the risks of perforating the posterior cortical bone and misaligning the fracture through quadriceps tension while inserting the nail.

In 2010, Morandi et $\mathrm{al}^{(13)}$ described a lateral 
suprapatellar route that they considered to be simpler than the medial routes, with easier access to the safe point of entry in the tibia. They indicated this not only for very proximal fractures but also for patients for whom the act of kneeling was important, or for whom there had been multiple trauma with injury to the soft tissue surrounding the patellar tendon, or furthermore, for multiple trauma patients for whom this route reduced the manipulation of other fractures, such as the femur and pelvis, during the treatment.

This new access route, of great interest in principle because it seems to reduce the incidence of anterior knee pain, presents risks to the intra-articular structures. These risks have not been properly studies in papers in the literature and, for this to be done, specific instruments with special dimensions and characteristics for this route firstly need to be developed, so that an assessment can then be made regarding which lesions might be caused by these instruments and, finally, a true indication for this new route can be made, in order to be able to use it safely.

The authors cited used adaptations from endoscopic cannulae and trocars, cut-down syringes and a variety of protectors until reaching the models currently used, which were developed from previous attempts and not from specific projects and analysis.

In the present study, we observed that it was very easy to locate the entry point through this route, even without using radioscopy. Positioning the guidewire totally blindly only injured the Hoffa fat in most cases. This structure is always crossed when using this routeoffa fatH. Only in one case was the guidewire positioned anteriorly to the entry point, thereby damaging the pes anserinus.

However, in four of the five cadavers studied, the start of the chondral surface of the femur became an obstacle that was difficult to overcome because of the very simple and flexible sleeve used, which was a syringe tube that was cut obliquely without the embolus.

In three knees, this elevated chondral surface could not be surmounted and, in another three knees, it suffered injury.

Thus, we defined this chondral surface of the anterior face of the knee as a limiting structure, and this should be used as a safety parameter when new studies are conducted using specific instruments to examine the lateral suprapatellar route for inserting a locked intramedullary nail in the tibia.

Such instruments need to be developed for subsequent in vivo use for follow-up regarding postoperative pain on the anterior face of the knee.

The lateral suprapatellar access route for placement of an intramedullary nail in tibial fractures is an alternative that may be viable with adequate instruments, which need to be developed through more controlled studies.

\section{CONCLUSION}

We conclude that the lateral suprapatellar access made it easy to locate the entry point for the guidewire of the intramedullary nail.

\section{REFERENCES}

1. Bhattacharyya T, Seng K, Nassif NA, Freedman I. Knee pain after tibial nailing: the role of nail prominence. Clin Orthop Relat Res. 2006;449:303-7.

2. Cartwright-Terry $M$, Snow $M$, Nalwad $H$. The severity and prediction of anterior knee pain post tibial nail insertion. J Orthop Trauma. 2007;21(6):381-5.

3. Toivanen JA, Väistö $O$, Kannus $P$, Latvala K, Honkonen SE, Järvinen MJ. Anterior knee pain after intramedullary nailing of fractures of the tibial shaft. A prospective, randomized study comparing two different nail-insertion techniques. J Bone Joint Surg Am. 2002;84(4):580-5.

4. Väistö $O$, Toivanen J, Kannus $P$, Järvinen $M$. Anterior knee pain after intramedullary nailing of fractures of the tibial shaft: an eight-year follow-up of a prospective, randomized study comparing two different nail-insertion techniques. J Trauma. 2008;64(6):1511-6.

5. Althausen PL, Neiman R, Finkemeier CG, Olson SA. Incision placement for intramedullary tibial nailing: an anatomic study. J Orthop Trauma. 2002;16(10):687-90.

6. Väistö $O$, Toivanen J, Paakkala T, Järvelä T, Kannus $P$, Järvinen M. Anterior knee pain after intramedullary nailing of a tibial shaft fracture: an ultrasound study of the patellar tendons of 36 patients. J Orthop Trauma. 2005;19(5):311-6.

7. Kakar S, Tornetta P 3rd. Open fractures of the tibia treated by immediate intramedullary tibial nail insertion without reaming: a prospective study. J Orthop Trauma. 2007;21(3):153-7.

8. Laflamme GY, Heimlich D, Stephen D, Kreder HJ, Whyne CM. Proximal tibial fracture stability with intramedullary nail fixation using oblique interlocking screws. J Orthop Trauma. 2003;17(7):496-502.

9. Bong MR, Koval KJ, Egol KA. The history of intramedullary nailing. Bull NYU Hosp Jt Dis. 2006;64(3-4):94-7.

10. Tornetta $P$ 3rd, Collins $E$. Semiextended position of intramedullary nailing of the proximal tibia. Clin Orthop Relat Res. 1996;(328):185-9.

11. Tornetta P 3rd, Riina J, Geller J, Purban W. Intraarticular anatomic risks of tibial nailing. J Orthop Trauma. 1999;13(4):247-51.

12. McConnell T, Tornetta $P$ 3rd, Tilzey J, Casey D. Tibial portal placement: the radiographic correlate of the anatomic safe zone. J Orthop Trauma. 2001;15(3):207-9.

13. Morandi M, Banka T, Gaiarsa GP, Guthrie ST, Khalil J, Hoegler J, et al. Intramedullary nailing of tibial fractures: review of surgical techniques and description of a percutaneous lateral suprapatellar approach. Orthopedics. 2010;33(3):172-9.

14. Kuntscher GB. The Kuntscher method of intramedullary fixation. J Bone Joint Surg Am. 1958;40(1):17-26.

15. Grosse A, Kempf I, Lafforgue D. [Treatment of fragments, loss of bony substance and pseudarthrosis of femur and tibia using screw fixation (40 cases)]. Rev Chir Orthop Reparatrice Appar Mot. 1978;64(Suppl 2):33-5.

16. Keating JF, Orfaly R, O'Brien PJ. Knee pain after tibial nailing. J Orthop Trauma. 1997;11(1):10-3.

17. Court-Brown CM, Gustilo T, Shaw AD. Knee pain after intramedullary tibial nailing: its incidence, etiology, and outcome. J Orthop Trauma. 1997;11(2):103-5.

18. Tornetta P 3rd, Ryan S. Tibial metaphyseal fractures: nailing in extension. In: Paper presented at: Orthopaedic Trauma Association $24^{\text {th }}$ Annual Meeting: October 16-18, 2008; Denver, Colorado. 